\title{
Which atypical antipsychotic?
}

\author{
CHRISTOPHER S. THOMAS and SHÔN LEWIS
}

The drug treatment of schizophrenia is changing. Until recently, drug development was focused mainly on selective dopamine $D_{2}$ receptor blockade. The re-discovery of clozapine, with its relatively low affinity for $D_{2}$ receptors, diverse pharmacology, yet superior clinical efficacy in treatmentresistant schizophrenia, has changed that. The basis for its improved action may be related to combined $\mathrm{D}_{2}$ and $5-\mathrm{HT}_{2}$ blockade. On this basis, a series of relatively non-toxic drugs are starting to emerge. These are called atypical antipsychotics because they do not provoke catalepsy in rats and have a clinical profile in which extrapyramidal side effects are not usually seen at clinically effective antipsychotic doses.

This group technically includes some older drugs such as thioridazine, loxapine and sulpiride as well as the selective $D_{2}$ blocker amisulpiride. Here we will focus on clozapine, and some of the newer atypical antipsychotics: risperidone, olanzapine, sertindole, quetiapine and ziprasidone. At the time of writing, the first four of these drugs are in clinical use in the UK. Ziprasidone will probably become available this year. They are relatively expensive, because conventional antipsychotic drugs are extremely cheap. We will look at five interrelated aspects of antipsychotic treatment: efficacy for positive and total symptom scores; efficacy for negative symptoms; efficacy in treatment-resistant schizophrenia; side-effects, and economic analyses.

\section{EFFICACY FOR POSITIVE SYMPTOMS}

Risperidone is more effective than placebo and as effective as haloperidol in the treatment of chronic schizophrenia (Marder \& Meibach, 1994). In this trial, 6, 10 and $16 \mathrm{mg}$ doses of risperidone and $20 \mathrm{mg}$ haloperidol were superior to placebo for positive symptoms. However, results were difficult to interpret because of chance group differences at baseline. In a larger study involving 1362 patients, Peuskens et al (1995) showed that 4, 8, 12 and $16 \mathrm{mg}$ risperidone were as good as $10 \mathrm{mg}$ haloperidol in reducing positive symptoms.

Song (1997), a health economist, undertook a meta-analysis of 11 randomised controlled trials. He concluded that risperidone is superior to placebo and at least as effective as conventional drugs (mainly haloperidol) in reducing the total symptom score (Brief Psychiatric Rating Scale (BPRS; Overall \& Gorham, 1962) or Positive and Negative Syndrome Scale (PANSS; Kay et al, 1987)) by $20 \%$. Mattes (1997), a clinical psychopharmacologist, is less sanguine about risperidone, pointing to flaws in the trial data, particularly with regard to selection of patients, who tended to be chronically hospitalised and to have responded poorly to haloperidol.

Olanzapine has been shown to be superior to placebo and as effective as 10-12 $\mathrm{mg}$ haloperidol in reducing BPRS total and BPRS positive symptoms in a multi-national trial (Beasley et al, 1996a). In a second, double-blind, acute phase study comparing 1 and $10 \mathrm{mg}$ doses of olanzapine with placebo, $10 \mathrm{mg}$ olanzapine was significantly more effective than placebo in reducing BPRS total, BPRS positive, PANSS total and PANSS positive scores (Beasley et al, 1996b). A large multi-centre study comparing olanzapine with haloperidol found significantly greater reductions in total BPRS, PANSS and Clinical Global Impression scores in the olanzapine group (Tollefson et al, 1997). This finding was on an intention-to-treat analysis, carrying forward the data on drop-outs from the last rating before they withdrew. Since half of the haloperidol arm and only onethird of the olanzapine arm dropped out, the finding of greater efficacy for olanzapine might be spurious.
In a six-week, double-blind, placebo controlled trial involving 280 patients, high-dose quetiapine was shown to be superior to placebo and to low-dose quetiapine in reducing total BPRS score; and to placebo in reducing BPRS positive symptom cluster score (Small et al, 1997). In a study comparing haloperidol, placebo and multiple doses of quetiapine, quetiapine was superior to placebo in reducing BPRS total score and BPRS positive symptom score and as effective as haloperidol (Arvanitis et al, 1997).

Sertindole is also effective for positive symptoms. In a double-blind placebo controlled study evaluating the efficacy of sertindole and haloperidol involving 497 patients, sertindole and haloperidol were comparable and both were superior to placebo on the BPRS total score and the PANSS positive symptom sub-scale (Zimbroff et al, 1997).

Ziprasidone has been shown to be superior to placebo on PANSS total score and BPRS total score at four weeks and at six weeks (Davis \& Markham, 1997).

\section{EFFICACY FOR NEGATIVE SYMPTOMS}

One widely disseminated claim about the atypicals is an effect on the negative symptoms of schizophrenia. A problem here is the heterogeneity of observed negative symptoms, especially when assessed by rating scales. Carpenter et al (1995) has distinguished "primary negative symptoms" of blunted affect and poverty of speech, from qualitatively similar symptoms which are secondary to severe positive symptoms, depression or drug side-effects. They may, paradoxically, respond to the addition of anticholinergic medication or a reduction in neuroleptic dose, adjunctive antidepressant medication or social measures.

Conventional antipsychotic medication may impair some aspects of cognition, although the evidence is far from conclusive (King, 1994). This has led to suggestions that some of the apparent benefit in negative symptoms associated with atypical antipsychotic medication may be due to a reduction in cognitive impairment (Casey, 1996).

Kane et al (1988) found clozapine to be superior to chlorpromazine in treatmentresistant schizophrenia on both positive and negative symptoms. Lieberman et al 
(1994) reported that negative symptoms responded to treatment approximately seven weeks after decreases in positive symptoms. However, debate ensued as to whether the main action of clozapine on negative symptoms is mediated through greater improvement in positive symptoms and fewer extrapyramidal symptoms, rather than an action on primary negative symptoms. Breier et al (1994) showed that clozapine was superior to haloperidol in treating positive and negative symptoms of chronic schizophrenia; but negative symptoms were significantly improved only in the subgroup of patients with "nondeficit" schizophrenia. This led Carpenter et al (1995) to conclude that treatment of primary negative symptoms is not supported by the current experimental data.

For the newer atypical antipsychotics, it is even more unclear whether they have a direct action on negative symptoms. In a meta-analysis of the pooled results from six double-blind trials, subjects given risperidone (4-8 $\mathrm{mg} /$ day) had a significantly higher negative symptom response rate than those receiving conventional antipsychotics (Carman et al, 1995). However, in the large ( $n=1362)$ multi-national double-blind study comparing risperidone with haloperidol, the changes on the negative subscale of the PANSS versus baseline in all treatment groups were not statistically different at end-point (Peuskens et al, 1995). In Song's (1997) metaanalysis of 11 randomised controlled trials, the difference in negative symptom scores between groups treated with risperidone and haloperidol was marginal. Superiority to placebo in treating negative symptoms on PANSS or the Scale for the Assessment of Negative Symptoms (SANS; Andreasen, 1982) has been reported in trials with olanzapine (Beasley et al, 1996a,b), sertindole (Zimbroff et al, 1997), quetiapine (Arvanitis et al, 1997) and ziprasidone (Davis \& Markham, 1997).

Subjecting the olanzapine results to a path analysis, designed to tease apart contributory effects, suggested this to be a genuine effect on primary negative symptoms (Tollefson \& Sanger, 1997).

Purists will say, probably correctly, that the case that any atypical improves primary negative symptoms has still not been made conclusively. Pragmatists will say, also correctly, that whether the negative symptoms which respond are primary or secondary is beside the point if the patient improves.

\section{EFFICACY IN TREATMENT. RESISTANT SCHIZOPHRENIA}

The reasons why some patients fail to respond to traditional antipsychotics include poor compliance, substance misuse and a range of psychosocial factors. Even when these reasons are excluded or reduced there remains $30 \%$ of patients who derive little benefit from conventional therapy (Kane et al, 1988).

Clozapine is superior to conventional antipsychotics in recalcitrant schizophrenia. In the three best double-blind randomised controlled trials of clozapine in treatment-resistant schizophrenia, response rates based on BPRS scores were $30 \%$ at six weeks (Kane et al, 1988) 44\% at 10 weeks (Breier et al, 1994) and $42 \%$ at 29 weeks (Umbricht et al, 1997) compared with response rates to chlorpromazine or haloperidol of 4,8 and $6 \%$, respectively. Longer-term studies have shown that some clozapine-treated patients return to employment and continue to function at a higher level. Indirect evidence suggests that clozapine may decrease the rate of suicide and deliberate self-harm (Meltzer \& Okali, 1995).

The efficacy of newer atypicals in treatment-resistant schizophrenia remains to be shown. Ames et al (1997) in a preliminary report of a double-blind trial showed risperidone to out-perform haloperidol, albeit modestly, in 87 treatmentresistant patients. Patients preferred risperidone. The results of open trials comparing risperidone with clozapine agree that clozapine is still the drug of choice (Ames et al, 1997), although the only published doubleblind comparison in 86 treatment-refractory patients found the two drugs to be almost equally effective (Bondolfi et al, 1996). In a report of preliminary doubleblind data, Conley et al (1997) showed olanzapine to be better than chlorpromazine in 84 treatment-resistant patients. No good data are yet available on the effectiveness of any new atypical in clozapineintolerant patients.

\section{ADVERSE EFFECTS}

The undisputed advantage of atypical antipsychotics over conventional agents is their relative lack of neurological side-effects, including dystonia, akathisia, drug-induced Parkinsonism and tardive dyskinesia. These side-effects contribute to non-compliance. Clozapine appears to have little or no extrapyramidal effects. It can cause neutropaenia, but the complications of this are precluded by blood monitoring. Other troublesome side-effects include hypersalivation, dry mouth, nausea, sedation, convulsions, hypotension, urinary incontinence and weight gain.

Risperidone in low doses ( $\leqslant 6 \mathrm{mg}$ ) is also relatively free from extrapyramidal side-effects; but at higher doses extrapyramidal side-effects emerge. It may also be associated with agitation, anxiety, headache, insomnia and nausea. With higher doses there appears to be an increasing incidence of sedation, blurred vision, orthostatic dizziness, weight gain and sexual dysfunction. None the less, risperidone has better subjective tolerability than either clozapine or conventional drugs.

Olanzapine and quetiapine have fewer extrapyramidal side-effects than risperidone, although such effects emerge with doses of olanzapine above $20 \mathrm{mg}$ per day. Both drugs can cause somnolence, headache and weight gain. As with risperidone, ziprasidone seems to cause extrapyradimal side-effects at high doses (above $160 \mathrm{mg}$ a day) but is relatively non-sedative. Preliminary data suggest it may have fewer sexual side-effects and cause less weight gain.

Sertindole similarly produces few or no extrapyramidal symptoms. It can cause nasal congestion, decreased ejaculatory volume, as well as weight gain. The effect of most concern hinges on a prolonged QT interval. Safety concerns have arisen from 16 deaths due to adverse cardiac events among 2194 patients who had participated in trials of sertindole (Barnett, 1996), although other antipsychotics can have such effects. In the UK it is now recommended that electrocardiograms are performed before treatment and then at three months and annually.

The improved tolerability of the new atypicals is likely to translate into better compliance. Definitive prospective studies of this are awaited.

\section{ECONOMIC ANALYSES}

Clozapine treatment can lead to improved social functioning and quality of life. As a consequence, there is often a reduced need 
for hospitalisation, but saving on hospitalisation costs are unlikely to accrue until at least two years of treatment (Revicki et al, 1990). A UK analysis, based on the US data of Revicki et al (1990) of one year's clozapine treatment, indicated that clozapine could be cost-effective or cost-neutral (Davies \& Drummond, 1993).

Economic data on other drugs are as yet only retrospective or computer-modelled. A retrospective study of risperidone in patients suffering from chronic schizophrenia showed a reduction in number of in-patient days compared with the previous year of a conventionally treated control group (Addington et al, 1993). In a decision-tree simulation model, olanzapine was compared with oral haloperidol over a hypothetical five-year period (Almond \& O'Donnell, 1998). Costs for the haloperidol-treated group were marginally more expensive because of the higher rate of relapse and development of adverse sideeffects leading to a change in medication.

\section{WHICH AT YPICAL ANTIPSYCHOTIC?}

First, a caveat. In respect of drug efficacy data, this overview is likely to be out of date by the time it is published. Indeed, it would be disappointing if it were not. A deluge of phase 3 and phase 4 trial results is imminent. The National Health Service has commissioned the University of York Centre for Reviews and dissemination to undertake a full systematic review of this area. Currently we believe the following to be safe conclusions.

The new atypical antipsychotics are as effective as conventional drugs for the acute symptoms of a schizophrenic illness. The evidence for a direct effect on primary negative symptoms is still unproven. Their indisputable advantage is their relative lack of neurological side-effects. A clear indication, therefore, is in patients in whom conventional antipsychotics at optimum dosage are causing such side-effects, bearing in mind that some established drugs, such as sulpiride, loxapine and thioridazine, carry fewer side-effects.

In treatment-resistant patients who have not responded to adequate trials of conventional antipsychotics, clozapine remains the drug of choice. There is little scientific evidence yet available for the use of other new atypicals in this situation.
Patients who have responded well to conventional drugs, including maintenance medication, without marked side-effects should continue on these drugs. The most intriguing question is the first-line use of new atypicals in first-episode patients.

Again, the data are not yet available but if fewer side-effects mean better compliance, then it might be in this patient group that the new drugs will have a particular place. However, many of the published trials report only short-term data and there are insufficient data on which to base long-term treatment for relapse prevention or determine which, if any, of the atypicals, with the exception of clozapine, produces the least tardive dyskinesia.

Of the new atypicals, risperidone has the advantage of having been available the longest. Trial data could be more extensive but suggest it is effective. In doses of $6 \mathrm{mg}$ a day it has fewer extrapyramidal side-effects than traditional drugs. Olanzapine may soon have a wider database than risperidone by which to judge its efficacy. Data so far suggest it is at least as effective as haloperidol and has fewer neurological side-effects than risperidone.

It is clear that, by virtue of $\mathrm{D}_{2} / 5-\mathrm{HT}_{2}$ blockade, the atypicals cause fewer extrapyramidal side-effects than older drugs. But the pattern with which they block other brain receptors varies considerably between drugs, which is reflected in different sideeffect profiles. $D_{2}$ affinity is quite high with risperidone, so that extrapyramidal sideeffects occur at higher doses, whereas quetiapine and sertindole lie at the other end of the spectrum, with few or no such effects.

Sertindole may face an uphill struggle now with mandatory electrocardiogram

Table I Comparative cost of antipsychotics

\begin{tabular}{lcccc}
\hline Drug & Usual dose & High dose & $\begin{array}{c}\text { Community cost/28 days } \\
\text { usual dose (high dose) }\end{array}$ & $\begin{array}{c}\text { Hospital cost/28 days } \\
\text { usual dose (high dose) }\end{array}$ \\
\hline Haloperidol & $8 \mathrm{mg}$ o.d. & $100 \mathrm{mg}$ & $€ 6.52(65.66)$ & $€ 1.53(11.84)$ \\
Sulpiride & $400 \mathrm{mg}$ b.d. & $2400 \mathrm{mg}$ & $€ 21.28(63.84)$ & $€ 10.53(31.58)$ \\
Thioridazine & $50 \mathrm{mg}$ t.d.s. & $800 \mathrm{mg}$ & $€ 2.89(15.01)$ & $€ 2.69(12.45)$ \\
Trifluoperazine & $10 \mathrm{mg}$ b.d. & $20 \mathrm{mg} \mathrm{q.d.s}$ & $€ 2.48(9.90)$ & $€ 0.86(3.43)$ \\
Olanzapine & $10 \mathrm{mg}$ o.d & $20 \mathrm{mg}$ o.d. & $€ 105.47(210.93)$ & $€ 109.06(218.12)$ \\
Quetiapine & $300 \mathrm{mg}$ & $750 \mathrm{mg}$ & $€ 105.56(237.44)$ & $€ 105.56(237.44)$ \\
Risperidone & $6 \mathrm{mg}$ o.d. & $16 \mathrm{mg}$ o.d. & $€ 109.20(288.29)$ & $€ 112.28(296.41)$ \\
Sertindole & $16 \mathrm{mg}$ o.d. & $24 \mathrm{mg}$ o. d. & $€ 102.55(136.74)$ & $€ 106.03(141.39)$ \\
Clozapine & $100 \mathrm{mg}$ t.d.s. & $300 \mathrm{mg}$ t.d.s. & $€ 150.15(450.45)$ & $€ 158.79(476.37)$ \\
\hline
\end{tabular}
Safety of Medicines has recently relaxed guidelines, and conventional antipsychotics can have similar effects on the myocardium. Weight gain may be related to $5-\mathrm{HT}_{2 \mathrm{C}}$ receptor blockade and can be marked with olanzapine, sertindole and quetiapine. Sexual dysfunction may be related to hyperprolactinaemia or to alpha-adrenergic effects and occurs slightly more frequently with risperidone and sertindole. Like clozapine, olanzapine has anticholinergic side-effects, such as dry mouth. As with conventional antipsychotics, sedation is linked to the antihistamine effects. It is most marked with olanzapine and, especially, quetiapine, although still not to the degree of some conventional drugs. Sedation can be an advantage in agitated patients, where atypicals without sedative properties might require an adjunctive benzodiazepine for a few days. Other differences between the new drugs include their half-life, which determines whether once daily dosage is possible. Intramuscular preparations will be available for some, such as ziprasidone, but long-acting depot preparations are still a long way off.

Since all these drugs are relatively expensive (Table 1), cost control is already an issue. Cost-effectiveness and cost-utility data are needed in real National Health Service settings comparing the new drugs with standard treatments and with each other, particularly focused on first-episode and treatment-resistant patients. Only then will we know the true worth of the new atypicals. If cost-effective, then there will need to be discussions between clinicians, managers, general practitioners and purchasers to develop strategies that will surveillance, although the Committee on 
CHRISTOPHER S. THOMAS. MD. SHÔN LEWIS, MD. University Hospital of South Manchester, Manchester M20 8LR

Correspondence: Dr Christopher Thomas. Consultant Psychiatrist. University Hospital of South Manchester. Nell Lane, Manchester M20 8LR

(First received 12 November 1996, final revision 4 November 1997, accepted II November 1997)

allow the redistribution of resources to fund these developments.

\section{DECLARATION OF INTERESTS}

Both authors have at various times received smal but significant honoraria from pharmaceutical companies in this field.

\section{REFERENCES}

Addington, D. E., Jones, B., Bloom, D., et al (1993) Reduction in hospital days in chronic schizophrenic patients treated with risperidone: a retrospective study Clinical Therapeutics, 15, 917-926.

Almond, S. \& O'Donnell, O. (1998) The cost effectiveness of olanzapine compared with haloperidol in the treatment of schizophrenia in the UK. Journal of Pharmacoeconomics, in press.

Ames, D., Wirshing, W. C., Marshall, B. D., et al (1997) Risperidone $v$ haloperidol in treatment resistant schizophrenia. Schizophrenıa Research, 24. 193-194.

Andreasen, N. C. (1982) Negative symptoms in schizophrenia. Archives of General Psychiatry. 39. 784-788

Arvanitis, L. A., Miller, B. G. \& the Seroquel Trial 13 Study Group (1997) Multiple fixed doses of "seroquel" (quetiapine) in patients with acute exacerbation of schizophrenia: a comparison with haloperidol and placebo. Bıological Psychiatry. 42. 233-246.

Barnett, A. (1996) Safety concerns over antipsychotic drugs: sertindole. Lancet, 348. 256.

Beasley, C. M., Tollefson, M. D., Tran, P., et al (1996a) Olanzapine versus placebo and haloperidol. Acute phase results of the North American double-blind olanzapine trial. Neuropsychopharmacology, 14, 111-123
_, Sanger, T., Satterlee, W., et al (1996b) Olanzapine versus placebo: results of a double blind fixed-dose olanzapine trial. Psychopharmacology. 124, 159- 167.

Bondolfi, G., Baumann, P. \& Dufour, H. (1996) Treatment-resistant schizophrenia: clinical experience with new antipsychotics. European

Neuropsychopharmacology, 6(suppl. 2). S2-\$25.

Breier, A., Buchanan, R.W., Kirkpatrick, B., et al (1994) Effects of clozapine on positive and negative symptoms in outpatients with schizophrenia. Americon Journal of Psychiatry, 15I, 20-26.

Carman, J., Peuskens, J. \& Vangeneugden, A. (1995) Risperidone in the treatment of negative symptoms of schizophrenia: a meta-analysis. International journal of Psychopharmacology. 10. 207-213.

Carpenter, W. T., Conley, R., Buchanan, R.W., et al (1995) Patient response and resource management: another view of clozapine treatment of schizophrenia. American journal of Psychiatry, 152, 827-832.

Casey, D. E. (1996) Extrapyramidal symptoms in old and new antipsychotics. Journal of Clinical Psychiatry. 57. 433-436

Conley, R., Tamminga, C. A. \& Beasley, C. (1997) Olanzapine vs. chlorpromazine in therapy refractory schizophrenia. Schızophrenıa Research, 24. 190.

Davies, L. M. \& Drummond, M. E. (1993) Assessment of costs and benefits of drug therapy for treatmentresistant schizophrenia in the United Kingdom. British Journal of Psychiatry. 162. 38-42

Davis, R. \& Markham, A. (1997) Ziprasidone. CNS Drugs, 8. 153-159.

Kane, J., Honigfeld, G., Singer, J., et al (1988) Clozapine for treatment resistant schizophrenia: a double blind comparison with chlorpromazine. Archives of General Psychiotry, 45. 789-796.

Kay, S. R., Fiszbein, A. Opler, L. A. (1987) The positive and negative syndrome scale (PANSS) for schizophrenia. Schizophrenı Bulletin. 13. 261-276.
King, D. J. (1994) Psychomotor impairment and cognitive disturbances induced by neuroleptics. Acto Psychiatrica Scandinavica, 89(suppl. 380), 53-58.

Lieberman, J. A., Safferman, A. Z., Pollack, S., et ol (1994) Clinical effects of clozapine in chronic schizophrenia: response to treatment and predictors of outcome. American journal of Psychiatry, 151, 1744-1752.

Marder, S. R. \& Meibach, R. C. (1994) Risperidone in the treatment of schizophrenia. American journal of Psychiatry. 151. 825-835.

Mattes, J. A. (1997) Risperidone: how good is the evidence of efficacy? Schizophrenı Bulletin. 23. 155-161.

Meltzer, H. Y. Okali, G. (1995) The reduction of suicidality during clozapine treatment in neuroleptic resistant schizophrenia: impact on risk - benef it assessment. American journal of Psychiatry, 152, 183-190.

Overall, J. E. \& Gorham, D. R. (1962) The brief psychiatric rating scale. Psychological Reports, 10. 799-812.

Peuskens J., on behalf of the Risperidone Study Group (1995) Risperidone in the treatment of patients with chronic schizophrenia: a multi-national, multicentre, double-blind, parallel-group study versus haloperidol. British journal of Psychiatry. 166, 712-726.

Revicki, D. A., Luce, B. R., Weschler, J. M., et al (1990) Cost-effectiveness of clozapine for treatment-resistant schizophrenic patients. Hospital and Community Psychiatry, 41. 850-854.

Small, J. G., Hirsch, S. R., Arvanitis, L. A., et al (1997) Quetiapine in patients with schizophrenia: a high and low dose double-blind comparison with placebo. Archives of General Psychiatry, 54, 549-557.

Song, F. (1997) Risperidone in the treatment of schizophrenia: a meta-analysis of randomised controlled trials. Journal of Psychopharmacology, II. 65-7I.

Tollefson, G. D. \& Sanger, T. M. (1997) Negative symptoms: a path analytic approach to a double blind, placebo- and haloperidol-controlled clinical trial with olanzapine. American journal of Psychiotry. 154. 466-474.

_, Beasley, C. M., Tran, P. V., et al (1997) Olanzapine versus haloperidol in the treatment of schizophrenia and schizoaffective and schizophreniform disorders: results of an international collaborative trial. Americon journal of Psychiatry. 154, 457-465

Umbricht, D., Ames, D., Wirshing, W. C., et al (1997) Predictors of response to clozapine in a long-term double blind treatment study. Schizophrenia Research, 24 189.

Zimbroff, D. L., Kane, J. M., Tamminga, C. A., et al (1997) Controlled, dose-response study of sertindole and haloperidol in the treatment of schizophrenia. American journal of Psychiatry, 154, 782-791. 